\title{
Analysis of allele frequencies of the selected 15 autosomal STR markers in Tikrit population - Iraq with comparison to Middle Eastern, African, and Europeans
}

\author{
Maan Hasan Salih ${ }^{\mathrm{a}^{*}}$, Akeel Hussain Ali Al-Assie ${ }^{\mathrm{a}}$, Majeed Arsheed Sabbah ${ }^{\mathrm{b}}$ \\ ${ }^{a}$ Department of Biology, College of Sciences, Tikrit University, Tikrit, Iraq \\ ${ }^{b}$ Forensic DNA Center for Research and Training, Al Nabrain University, Bagbdad, Iraq
}

Received 30th September 2020 / Accepted 29th March 2021

\begin{abstract}
Short tandem repeats (STRs) have been recommended as the highest polymorphic loci among the humana DNA regions. Therefore, STRs are agreeable to many genetic fields like forensic, population genetics and anthropological studies. The main aim of this research is to evaluate the autosomal STRs in Tikrit city-Iraq, to expand the human genetics database and forensic genetics analysis. The DNA database was obtained from 306 unrelated volunteers from native Tikrit population-Iraq, using 15 autosomal STR loci. The current study determined the allele frequencies in the Tikrit population and then compared them with other national Iraqi populations as well as with populations in the Middle East, Africa, and Europe. The highest level of heterozygosity was observed in D8S1179 and TH01 loci (0.797), while the less level was shown by CSF1PO (0.48). The departure from HWE Equilibrium was recorded in only 3 STR loci from a total of 15 loci analyzed $(\mathrm{p}<0.003)$. The Combined Match Probability (CMP) for 15 autosomal STR was 1 in $7.89208 \times 10^{-19}$ and the Combined Discrimination Power (CDP) was 0.9999999997. The discrimination power (DP) was especially high in D2S1338, D18S51, D19S433 and D21S11. Based on the results observed in a Dendrogram, Tikrit population was clustered with other populations, likely reflecting the historical and geographical factors. D2S1338, D18S51, D19S433 and D21S11 markers were recognized as suitable for forensic genetics analysis in Tikrit population. Also, the 15 STRs markers provide information for the studies of genetic distances between the current study and other included populations to be compared with this study.
\end{abstract}

Keywords: Allele frequencies, Forensic, Iraq, STR, Tikrit

\section{INTRODUCTION}

Ancient Mesopotamia (Iraq) is the area between the Tigris and the Euphrates rivers. Mesopotamia is indeed the home of the first appearing civilizations, including those of Sumer, Akkad, Babylon, and Assyria (Al-Quraishi and Negm, 2019). Tikrit is one of the oldest small cities in Iraq, located as a fort on the edge of the Tigris. Historically, the first mentioning of Tikrit is in 615
BC. During the Fall of Assyria Chronicle, it was a shield for Nabopolassar (the Babylonian king) at the time of his campaign on the Assur city (Bradford, 2001). Today, Tikrit city is the center of Salah al-Din Governorate, north-central Iraq. It stands on the west bank of the Tigris River approximately 100 miles northwest of Baghdad as shown in Figure 1. Notably, Tikrit's population is

*Author for correspondence: Maan Hasan Salih, Department of Biology, College of Sciences, Tikrit University, Tikrit, Iraq. Email maan.hasan@tu.edu.iq 
now mainly Arabs. It has three main groups: AlTikriti (containing some subpopulation), Alhadithi and Al-Bu Nasir. In Tikrit's population, the social organization, historical and geographical factors are expected to have a profound impact on the patterns of the population's genetic structure.

An individual's genetic profile is made up of several markers that are inherited from their parents (Delgado and Neyra, 2019). Studies in human molecular anthropology are interested with a large range of molecular markers (DNA markers), each marker having a different advantage but complementary to other markers (Garrigan and Hammer, 2006). Short tandem repeats (STRs) loci, or so-called microsatellites loci, occur as tandem repetitive sequences ranging of length from one to six bp and representing around $\sim 0.03 \%$ of the whole nuclear DNA (Gymrek, 2017). Short tandem repeat (STR) loci are the most informative genetic markers used worldwide for human identification (HID) purposes (Quiroz-Mercado et al., 2017). STRs are robust molecular markers that are used due to their high rate of hypervariability and vast distribution across the nuclear DNA (Yoo et al., 2011). Likewise, data analyses of STR loci have become important tools in common evolutionary researches (Bentayebi et al., 2014; and Reinar et al.,
2018). Because of the high mutation rate, autosomal STRs loci have the possibility to yield genetic evidence around recent evolutionary events in the history of human population, which make them the ideal option in population genetics studies and the forensic field (Chbel et al., 2003; El Amri et al., 2011; Pilav et al., 202). The allele frequency of STR-loci varies within/between populations and geographic region (Silva et al., 2012; Buadu, 2018). Therefore, several prior studies have investigated allele frequencies in the national Iraqi populations by using STR markers, such as; allele Frequency in $\mathrm{Al}$ Anbar population among 132 unrelated healthy individuals (Aljanabi et al., 2016), 302 unrelated individuals from the Kurdistan Population region (Murad and Amin, 2017), 120 samples of unrelated individuals from Wasit population, (Al-Rubai et al., 2015), and 100 individuals from Mesan and Basrah population (Hameed et al., 2015). This study is the first genetics characterization of Tikrit population, using 15 autosomal STRs in AmpFLSTR Identifiler Plus kit from the Applied Biosystems company (Foster City, USA). The current study consists of unrelated individuals from Tikrit / Iraq population who were selected to characterize the allele frequencies, forensic descriptive parameters and anthropological studies.

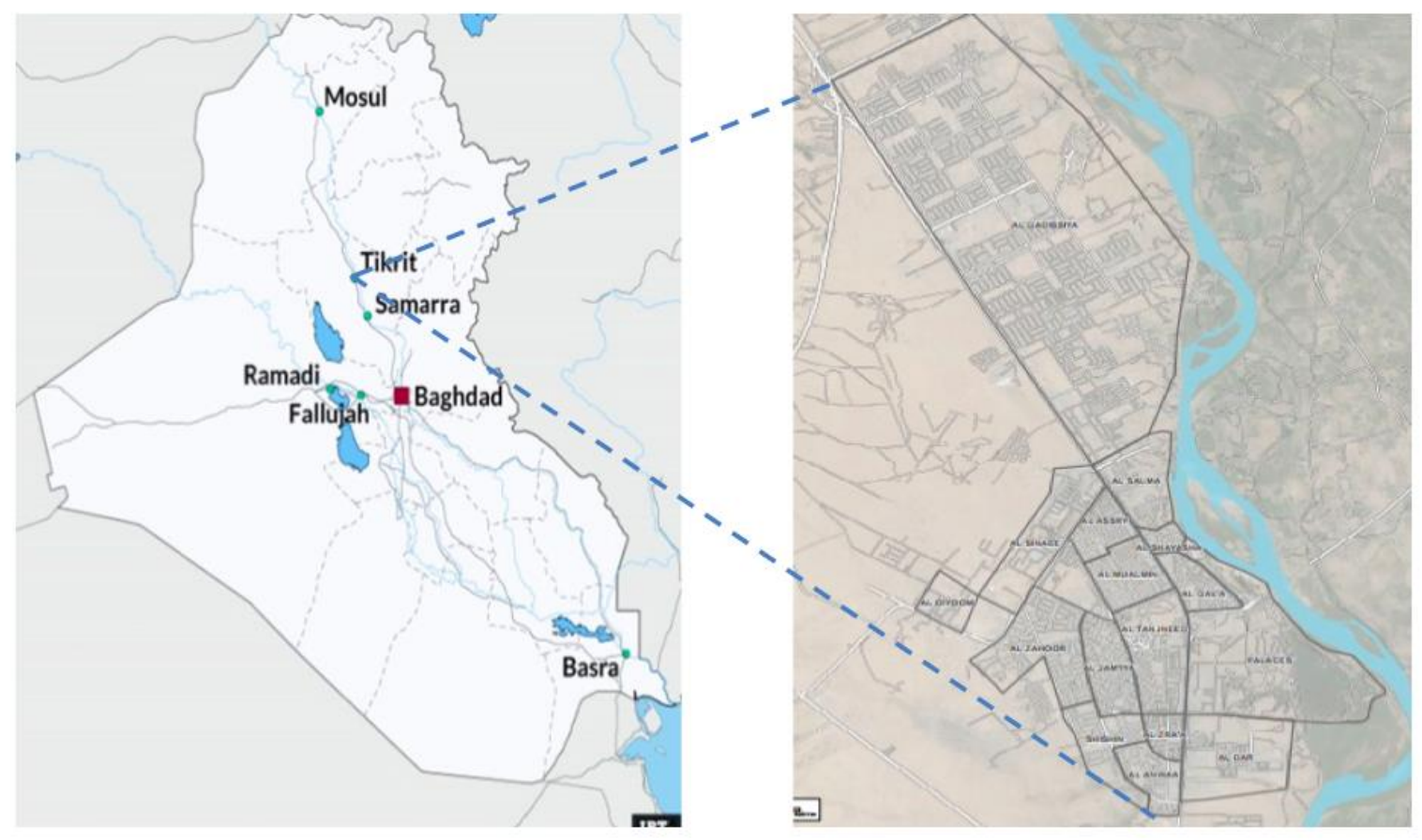

Figure 1. Geographic location of Tikrit city / Iraq. 


\section{MATERIALS AND METHODS}

\section{Samples collection}

In the current study, three hundred and six blood samples from healthy unrelated persons were spotted on FTA Card (GE Healthcare, UK). All samples originate from the native Tikrit population (Al-Tikriti, Alhadithi, and Al-Bu Nasir human tribes). All were volunteers who were chosen to achieve a maximum representation of native tribal groups who have lived in Tikrit city for at least two generations. Also, general information about the participants, their parents and grandparents are self-reported. The age of the individuals involved ranged from 18 to 60 years old (170 males and 136 females).

\section{DNA extraction}

Based on the manufacturer's instructions, a 1.2 $\mathrm{mm}$ punch from FTA card contains around 5-20 ng of genomic DNA (Alaeddini, 2012). DNA is isolated using the Chelex 100 resin methods with some modification (GE Healthcare, 2010). Then, DNA concentration and quality were measured by NanoDrop-1000 spectrophotometry (Thermo Scientific) based on the manufacturer's protocol.

\section{DNA amplification and data analysis}

From each sample, $1 \mathrm{ng} / \mu \mathrm{l}$ of genomic extracted DNA was amplified using $15+1$ STR markers (D8S1179, D21S11, D7S820, CSF1PO, D3S1358, THO1, D13S317, D16S539, D2S1338, D19S433, vWA, TPOX, D18S51, D5S818 and FGA) as well as amelogenin (gender-determining locus ) by using the Human Identification Kit, AmpFLSTR Identifiler Plus Kit from Applied Biosystems (Foster City, USA) and the GeneAmp PCR system 9700 from Applied Biosystems (Foster City, CA, USA) according to standards recommended by the manufacturer. The PCR program includes three stages: Stage one: $95^{\circ} \mathrm{C} / 11 \mathrm{~min}$., Stage two: $94^{\circ} \mathrm{C} / 20 \mathrm{sec}, 59^{\circ} \mathrm{C} / 3$ min., and Stage three: $60^{\circ} \mathrm{C} / 10 \mathrm{~min}$. final hold: $4^{\circ} \mathrm{C}$ up to 24 hours as shown in Table 1 . An Electrophoresis for PCR product was performed on the ABI 3500xl Genetic Analyzer with 8capillary from Thermo Fisher Scientific Company (Carlsbad, USA). The GeneMapper1 ID software (version 3.1) was used for the allele's identification and data analysis.

Table 1. PCR program.

\begin{tabular}{|c|c|c|c|c|}
\hline $\begin{array}{c}\text { Initial incubation } \\
\text { step }\end{array}$ & \multicolumn{2}{|c|}{ Cycle (28 cycles) } & Final extension & Final hold \\
\hline \multirow{2}{*}{ HOLD } & Denature & Anneal / Extend & \multirow{2}{*}{ HOLD } & \multirow{2}{*}{ HOLD } \\
\hline & \multicolumn{2}{|c|}{ Cycle } & & \\
\hline $95^{\circ} \mathrm{C}$ & $94^{\circ} \mathrm{C}$ & $59^{\circ} \mathrm{C}$ & $60^{\circ} \mathrm{C}$ & $4^{\circ} \mathrm{C}$ \\
\hline $11 \mathrm{~min}$ & $20 \mathrm{sec}$ & $3 \min$ & $10 \mathrm{~min}$ & Up to 24 hours \\
\hline
\end{tabular}

Table 2. Comparative populations with Tikrit population

\begin{tabular}{clc}
\hline Region & \multicolumn{1}{c}{ Population } & Population size \\
\hline \multirow{2}{*}{ Iraq } & Mesan and Basrah (Hameed et al., 2015 & 100 \\
& Wasit (Al-Rubai et al., 2015) & 120 \\
& Kurdistan (Murad and Amin, 2017) & 302 \\
& Al-Anbar (Al-Janabi et al., 2016) & 132 \\
\hline \multirow{2}{*}{ Middle East } & Riyadh / KSA (Osman et al., 2015) & 190 \\
& Jordan (Al-Eitan and Tubaishat, 2018) & 500 \\
\hline \multirow{2}{*}{ Africa } & Moroccan (Bentayebi et al., 2014) & 320 \\
& Sudan (Babiker et al., 2011) & 498 \\
\hline Europe & Swedish population (Montelius et al., 2008) & 416 \\
\hline Asia & Eastern Turkey (Tokdemir et al., 2016) & 802 \\
\hline
\end{tabular}




\section{Comparative populations}

Tikrit population data was used for comparison with the four national Iraqi populations. Two population were from the Arab Middle East, two populations from Arab Africa, one population from Europe and one population from Asia. See Table 2 for more details.

\section{Statistical analysis}

The calculation of Allele frequency, test HardyWeinberg Equilibrium (HWE) and p-value were performed with Genepop 4.7.5 software, using the Bonferroni corrected test (Glaubitz, 2004; Rousset, 2016). Linkage Disequilibrium (LD) observed and expected heterozygosity, and Fstatistics were evaluated using the Arlequin software v3.01 (Rousset, 2016). Forensic parameters including Polymorphic Information Contents (PIC), the Power of Discrimination (PD), Random Matching Probability (RMP) and the Probability of Exclusion (PE) calculated all these parameters manually by using Microsoft Office Excel (Version 2010) and GenAlEX (v.6.5) (Excoffier et al., 2009). Additionally, Dendrogram analysis was performed by using XLSTAT (Version 2020.1).

\section{RESULTS AND DISCUSSION}

The 306 samples from the Tikrit population-Iraq were subjected to 15 autosomal STR analysis. Figure 2 represents an example of DNA profiling for one sample (male) with STRs markers. Data of allele frequencies are listed in Table 3. The Observed and Expected heterozygosity, P-value, standard deviations and inbreeding coefficient for the STR loci are listed in Table 4. The total number of recorded STRs alleles was 153 and the allele frequency in a population ranged from 0.002 - 0.525. The highest allele number observed at D2S1338 and D19S433 loci was ( $\mathrm{n}=15)$, while the TPOX locus recorded the lowest number of alleles $(n=6)$. Allele 8 in the TPOX locus appear as the most polymorphic alleles. Basically, increasing size of sample translates to increase the accuracy of the allele frequency estimates in population (Hale et al., 2012). The highest heterozygosity is 0.797 for both D8S1179 and TH01 loci, while the lowest level was identified in
CSF1PO (0.48). Among the autosomal STR makers, F-statistical analyses detected a FIS value ranging from D5S818 (-0.048445) to CSF1PO $(0.327640)$. If the inbreeding coefficient is zero (i.e., random mating), the genotype frequencies are those expected for Hardy-Weinberg equilibrium. On the other hand, if there is a complete inbreeding $(F=1)$, the frequency of heterozygotes is zero, while the negative value of FIS means more heterozygotes than expected under HWE (Pyeritz, 2018). No linkage disequilibrium (LD) was detected among 15 STRs loci in population samples. Only 3 out of 15 STR loci showed significant deviation from expectations of HWE (Bonferroni corrected threshold $\mathrm{p}<0.003)$. Human populations do not exactly meet all the conditions of HWE (Padmanabhan, 2014). This deviation was imputed to the popular of consanguineous marriage, the marriage between relatives among Tikrit population increasing homozygosity. In findings of previous studies, some loci did not conform to HWE such as; Al-Anbar study which observed 4 out of 15 STR loci (Al-janabi et al.,2016), Wasit study with 3 of 15 observed and 4 of 15 STR loci (Al-Rubai et al., 2015), and a Saudi study which recorded 3 out of 15 STR loci (Osman and Alsafar, 2015) which is consistent with our data. Population Genetic structure can be affected broadly by cultural histories and genetic evolution which can change the frequencies of different variants at given genetic markers (Adnan et al., 2020).

Markers that are used for human identification may have weaker discrimination power in populations with genetic structure than in unstructured populations, due to the impact that the presence of subpopulation groups has on the random match probability (Haidar et al., 2021). The Polymorphic Information Content (PIC) was greater than 0.6 through all autosomal STR loci. Therefore, these results indicated that STR markers are highly polymorphic DNA markers and would be suitable as valuable markers for discriminating descent of persons in Tikrit population. Any markers of loci containing larger numbers of alleles are expected to have higher PIC values and thus are more instructive (Hildebrand et. al., 1994). The analyses of the results are set out in Table 5. It can be seen that the power of discrimination (PD) index for 
marker D2S1338 is 0.977 is the highest, followed by $\mathrm{D} 18 \mathrm{~S} 51$ at $0.970, \mathrm{D} 19 \mathrm{~S} 433$ at 0.952 and D21S11 at 0.950. In contrast, the marker with the lowest PD index is D2S1338 at 0.827. This indicates that a DNA-based database for Tikrit population can be safely used by using STRs loci. Within each STR marker, the discrimination power of an allele depends on its frequency in a certain human population (El Andari et al., 2018). The higher PD of a genetic locus led to the increased efficiency in power discrimination between individuals of the human population (AlSnan et al., 2019). The Combined Discrimination Power (CDP) of the examined 15 loci was 0.9999999997 which should be sufficient enough for the particular individual identification even if the census size of the population is extremely large. The highest and lowest Matching probability values were measured for the D3S1358 (0.166) and D2S1338 (0.023) loci, respectively. In the current study, the combined match probability was $7.89208 \times 10^{-19}$. This means that the probability of finding two persons with an identical DNA profile in Tikrit population is impossible. The observed values of the power of exclusion (PE) ranged from 0.171 at CSF1PO to 0.668 at $\mathrm{D} 2 \mathrm{~S} 1338$. The combined exclusion probability (CEP) was 0.92092 for all autosomal STR loci used.

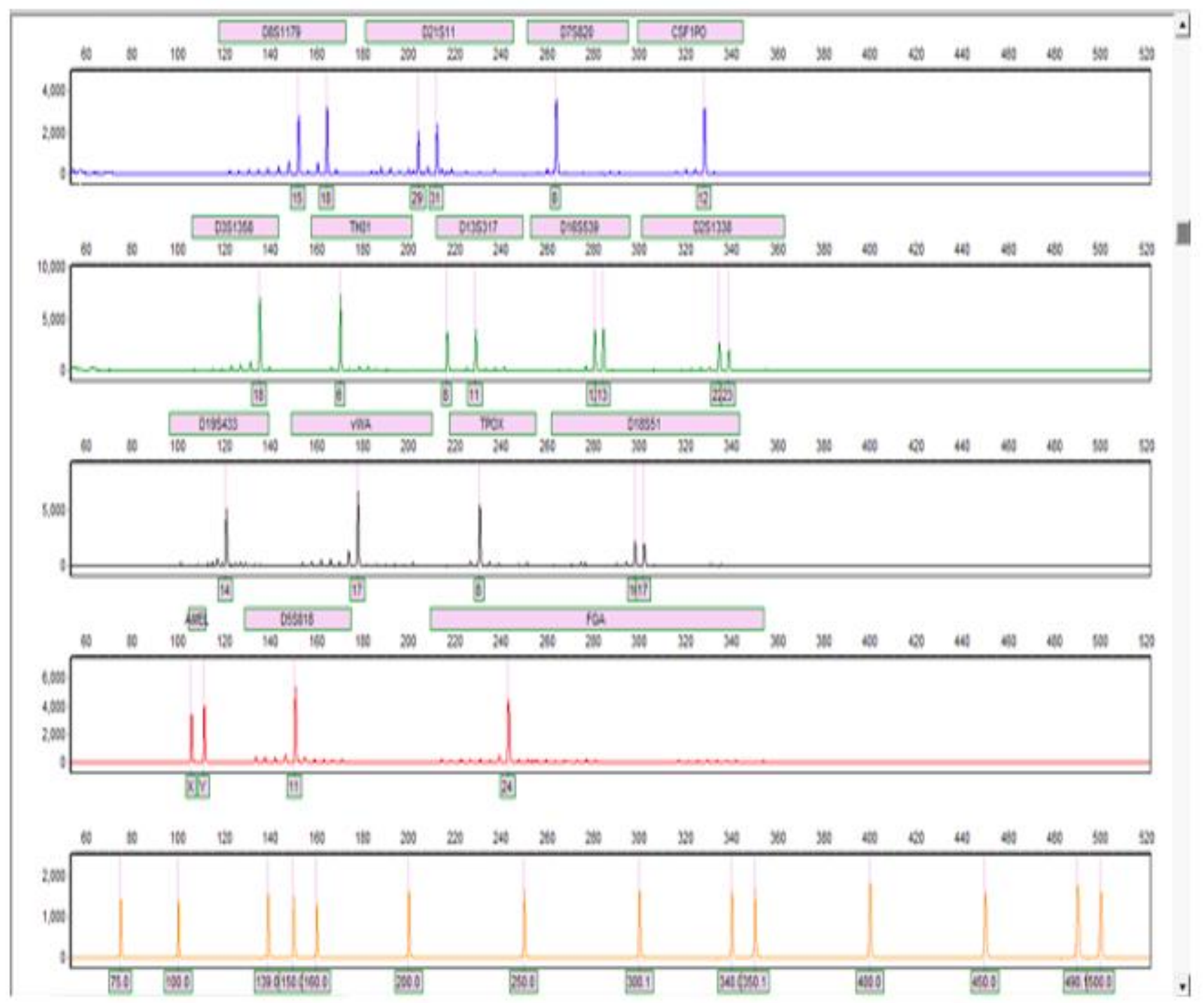

Figure 2. Electropherogram showing results of STR typing. 
Table 3(a). Allele frequency results for 8 of 15 autosomal STR markers.

\begin{tabular}{|c|c|c|c|c|c|c|c|c|c|c|c|c|c|c|c|c|}
\hline \multirow{2}{*}{ N0 } & \multicolumn{2}{|c|}{ D8S1179 } & \multicolumn{2}{|c|}{ D21S11 } & \multicolumn{2}{|c|}{ D7S820 } & \multicolumn{2}{|c|}{ CSF1PO } & \multicolumn{2}{|c|}{ D3S1358 } & \multicolumn{2}{|c|}{ TH01 } & \multicolumn{2}{|c|}{ D13S317 } & \multicolumn{2}{|c|}{ D16S539 } \\
\hline & Allele & Freq. & Allele & Freq. & Allele & Freq. & Allele & Freq. & Allele & Freq. & Allele & Freq. & Allele & Freq. & Allele & Freq. \\
\hline 1 & 8 & 0.007 & 27 & 0.011 & 7 & 0.031 & 7 & 0.002 & 12 & 0.003 & 5 & 0.01 & 8 & 0.126 & 8 & 0.062 \\
\hline 2 & 10 & 0.085 & 28 & 0.134 & 8 & 0.204 & 8 & 0.003 & 13 & 0.002 & 6 & 0.325 & 9 & 0.082 & 9 & 0.183 \\
\hline 3 & 11 & 0.116 & 29 & 0.225 & 9 & 0.075 & 9 & 0.029 & 14 & 0.039 & 7 & 0.175 & 10 & 0.062 & 10 & 0.08 \\
\hline 4 & 12 & 0.105 & 29.2 & 0.002 & 10 & 0.27 & 10 & 0.364 & 15 & 0.261 & 8 & 0.15 & 11 & 0.337 & 11 & 0.288 \\
\hline 5 & 13 & 0.275 & 30 & 0.261 & 11 & 0.296 & 11 & 0.312 & 16 & 0.333 & 9 & 0.208 & 12 & 0.284 & 12 & 0.229 \\
\hline 6 & 14 & 0.222 & 30.2 & 0.048 & 12 & 0.101 & 12 & 0.23 & 17 & 0.237 & 9.3 & 0.103 & 13 & 0.07 & 13 & 0.149 \\
\hline 7 & 15 & 0.149 & 31 & 0.041 & 13 & 0.018 & 13 & 0.054 & 18 & 0.108 & 10 & 0.029 & 14 & 0.039 & 14 & 0.005 \\
\hline 8 & 16 & 0.036 & 31.2 & 0.094 & 14 & 0.005 & 14 & 0.005 & 19 & 0.008 & & & & & & \\
\hline 9 & 17 & 0.003 & 32 & 0.018 & & & & & 20 & 0.002 & & & & & & \\
\hline 10 & 18 & 0.003 & 32.2 & 0.125 & & & & & 26 & 0.003 & & & & & & \\
\hline 11 & & & 33.2 & 0.033 & & & & & 28 & 0.002 & & & & & & \\
\hline 12 & & & 34.2 & 0.01 & & & & & & & & & & & & \\
\hline
\end{tabular}

Table 3(b). Allele frequency results for 7 of 15 autosomal STR markers.

\begin{tabular}{|c|c|c|c|c|c|c|c|c|c|c|c|c|c|c|}
\hline \multirow{2}{*}{ No } & \multicolumn{2}{|c|}{ D2S1338 } & \multicolumn{2}{|c|}{ D19S433 } & \multicolumn{2}{|c|}{ vWA } & \multicolumn{2}{|c|}{ TPOX } & \multicolumn{2}{|c|}{ D18S51 } & \multicolumn{2}{|c|}{ D5S818 } & \multicolumn{2}{|c|}{ FGA } \\
\hline & Allele & Freq. & Allele & Freq. & Allele & Freq. & Allele & Freq. & Allele & Freq. & Allele & Freq. & Allele & Freq \\
\hline 1 & 12 & 0.002 & 11 & 0.008 & 11 & 0.002 & 6 & 0.002 & 9 & 0.002 & 7 & 0.004 & 17 & 0.003 \\
\hline 2 & 14 & 0.002 & 11.2 & 0.002 & 14 & 0.051 & 8 & 0.525 & 10 & 0.016 & 8 & 0.016 & 18 & 0.01 \\
\hline 3 & 16 & 0.03 & 12 & 0.105 & 15 & 0.085 & 9 & 0.126 & 11 & 0.033 & 9 & 0.082 & 19 & 0.039 \\
\hline 4 & 17 & 0.133 & 12.2 & 0.005 & 16 & 0.328 & 10 & 0.07 & 12 & 0.132 & 10 & 0.103 & 20 & 0.121 \\
\hline 5 & 18 & 0.146 & 13 & 0.239 & 17 & 0.255 & 11 & 0.239 & 13 & 0.198 & 11 & 0.301 & 21 & 0.18 \\
\hline 6 & 19 & 0.125 & 13.2 & 0.047 & 18 & 0.203 & 12 & 0.039 & 14 & 0.144 & 12 & 0.283 & 22 & 0.137 \\
\hline 7 & 20 & 0.143 & 14 & 0.261 & 19 & 0.062 & & & 14.2 & 0.002 & 13 & 0.203 & 23 & 0.211 \\
\hline 8 & 21 & 0.057 & 14.2 & 0.054 & 20 & 0.011 & & & 15 & 0.124 & 14 & 0.005 & 24 & 0.19 \\
\hline 9 & 22 & 0.072 & 15 & 0.087 & 26 & 0.002 & & & 16 & 0.121 & 15 & 0.005 & 24.2 & 0.005 \\
\hline 10 & 23 & 0.113 & 15.2 & 0.088 & 28 & 0.002 & & & 17 & 0.105 & & & 25 & 0.083 \\
\hline 11 & 24 & 0.093 & 16 & 0.036 & & & & & 18 & 0.065 & & & 26 & 0.01 \\
\hline 12 & 25 & 0.062 & 16.2 & 0.041 & & & & & 19 & 0.036 & & & 27 & 0.008 \\
\hline 13 & 26 & 0.015 & 17 & 0.005 & & & & & 20 & 0.018 & & & 28 & 0.002 \\
\hline 14 & 27 & 0.005 & 17.2 & 0.021 & & & & & 21 & 0.005 & & & 29 & 0.002 \\
\hline 15 & 28 & 0.002 & 18 & 0.002 & & & & & & & & & & \\
\hline
\end{tabular}


Table 4. Observed and Expected heterozygosity, P-value, standard deviations and inbreeding coefficient.

\begin{tabular}{cccccc}
\hline Fis or f & s.d. & P-value & HE & HO & Locus \\
\hline D8S1179 & 0.797 & 0.821 & 0.92746 & 0.00022 & 0.030362 \\
D21S11 & 0.739 & 0.835 & 0.00194 & 0.00004 & 0.122633 \\
D7S820 & 0.758 & 0.782 & 0.00718 & 0.00009 & 0.030745 \\
CSF1PO & 0.48 & 0.714 & 0.00000 & 0.00000 & 0.327640 \\
D3S1358 & 0.742 & 0.752 & 0.00576 & 0.00006 & 0.012593 \\
TH01 & 0.797 & 0.787 & 0.35013 & 0.00052 & -0.016360 \\
D13S317 & 0.706 & 0.774 & 0.00713 & 0.00008 & 0.089464 \\
D16S539 & 0.742 & 0.8 & 0.05642 & 0.00016 & 0.071792 \\
D2S1338 & 0.836 & 0.891 & 0.50872 & 0.00040 & 0.061160 \\
D19S433 & 0.784 & 0.841 & 0.00069 & 0.00003 & 0.071621 \\
VwA & 0.748 & 0.773 & 0.13287 & 0.00027 & 0.032658 \\
TPOX & 0.644 & 0.646 & 0.69231 & 0.00034 & 0.007180 \\
D18S51 & 0.833 & 0.875 & 0.82387 & 0.00023 & 0.048181 \\
D5S818 & 0.81 & 0.772 & 0.02232 & 0.00012 & -0.048445 \\
FGA & 0.791 & 0.846 & 0.00441 & 0.00007 & 0.063759 \\
\hline
\end{tabular}

$\mathrm{HO}=$ Observed Heterozygosity; $\mathrm{HE}=$ Expected Heterozygosity $;$ P-value $=$ the $\mathrm{p}$ values of the exact test for Hardy-Weinberg equilibrium; s.d. = standard deviations; Fis $=$ F-Statistics test at $\mathrm{P}<0.05$

Table 5. Summary of forensic statistics parameters.

\begin{tabular}{ccccc}
\hline Locus & MP & PD & PIC & PE \\
\hline D8S1179 & 0.056 & 0.944 & 0.80 & 0.594 \\
D21S11 & 0.05 & $\mathbf{0 . 9 5 0}$ & 0.81 & 0.490 \\
D7S820 & 0.083 & $\mathbf{0 . 9 1 7}$ & 0.75 & 0.524 \\
CSF1PO & 0.136 & 0.864 & 0.66 & 0.171 \\
D3S1358 & 0.166 & 0.844 & 0.71 & 0.496 \\
TH01 & 0.08 & 0.920 & 0.76 & 0.594 \\
D13S317 & 0.087 & 0.913 & 0.74 & 0.437 \\
D16S539 & 0.069 & 0.931 & 0.77 & 0.496 \\
D2S1338 & 0.023 & $\mathbf{0 . 9 7 7}$ & $\mathbf{0 . 8 8}$ & 0.668 \\
D19S433 & 0.048 & $\mathbf{0 . 9 5 2}$ & 0.82 & 0.570 \\
VwA & 0.089 & 0.911 & 0.74 & 0.507 \\
TPOX & 0.023 & 0.827 & $\mathbf{0 . 6}$ & 0.347 \\
D18S51 & 0.030 & 0.970 & 0.86 & 0.662 \\
D5S818 & 0.105 & 0.895 & 0.74 & 0.619 \\
FGA & 0.044 & $\mathbf{0 . 9 5 6}$ & 0.83 & 0.582 \\
\hline
\end{tabular}

$\overline{\mathrm{PIC}}=$ Polymorphism information content $\mathrm{PD}=$ Power of Discrimination; MP $=$ Matching probability; PE $=$ Power of Exclusion

To estimate a differentiation between Tikrit populations and other populations that include national, Middle east, Afro-Arab, Asia and Europe populations, a Dendrogram was conducted based on the data of allele frequencies obtained from the 15 autosomal STRs. Thus, a Dendrogram was used in our study to exemplify the genetic distances between Tikrit populations and four national populations as in Figure 3, while Figure 4 showed genetics distance between Tikrit population- Iraq and other population listed in Table 2.

As shown in Figure 3, Tikrit, the Tikrit population shared the most genetic relatedness with the Al-Anbar, Kurdistan, and Wasit populations. On the other, Mesan and Basrah population showed relatedness with each other and in distant genetic structure from Tikrit population. The Tikrit population occupy an intermediate location between Al-Anbar and Kurdistan in one hand and Wasit population in 
other hand. Also, Figure 4 compares the genetic distance between Tikrit population/Iraq and some other international populations. Thus, Tikrit and Jordan populations share the most genetic relatedness among the other populations, followed by Sudan Morocco, Eastern Turkey and Riyadh KSA in the same cluster. On the other hand, Swedish population showed a distant genetic structure from Tikrit population.

At present, comprising investigation of human genetics population can illustrate the migration, gene flow, mutation and introduction history. However, due to the complicated effects of geography and history factors, the genetic distance varies among human populations. Also, results from previous researches of large STRs marker panels showed wide geographic clustering, which leads to a discussion about whether a human fine-scale genetic variation between human population is better characterized by separate clusters or continuous clines (Rosenberg et al., 2005; Perez et al., 2018 ). Besides, studies involving molecular archaeology can give extra information which is useful to interpret important global phenomena such as early migration, arising civilizations and human biology (Ariffin et al., 2007; Hunter et al., 2007).

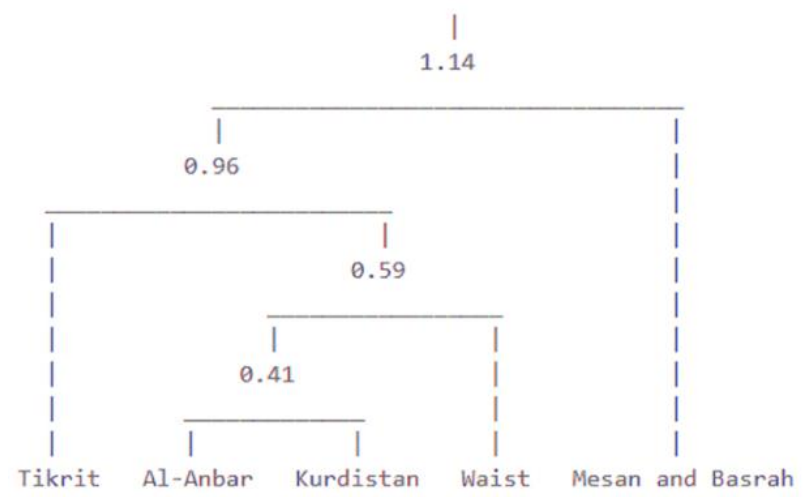

Figure 3. Dendrogram represent the level of similarity between Tikrit population and other Iraqi national populations.

\subsection{2}

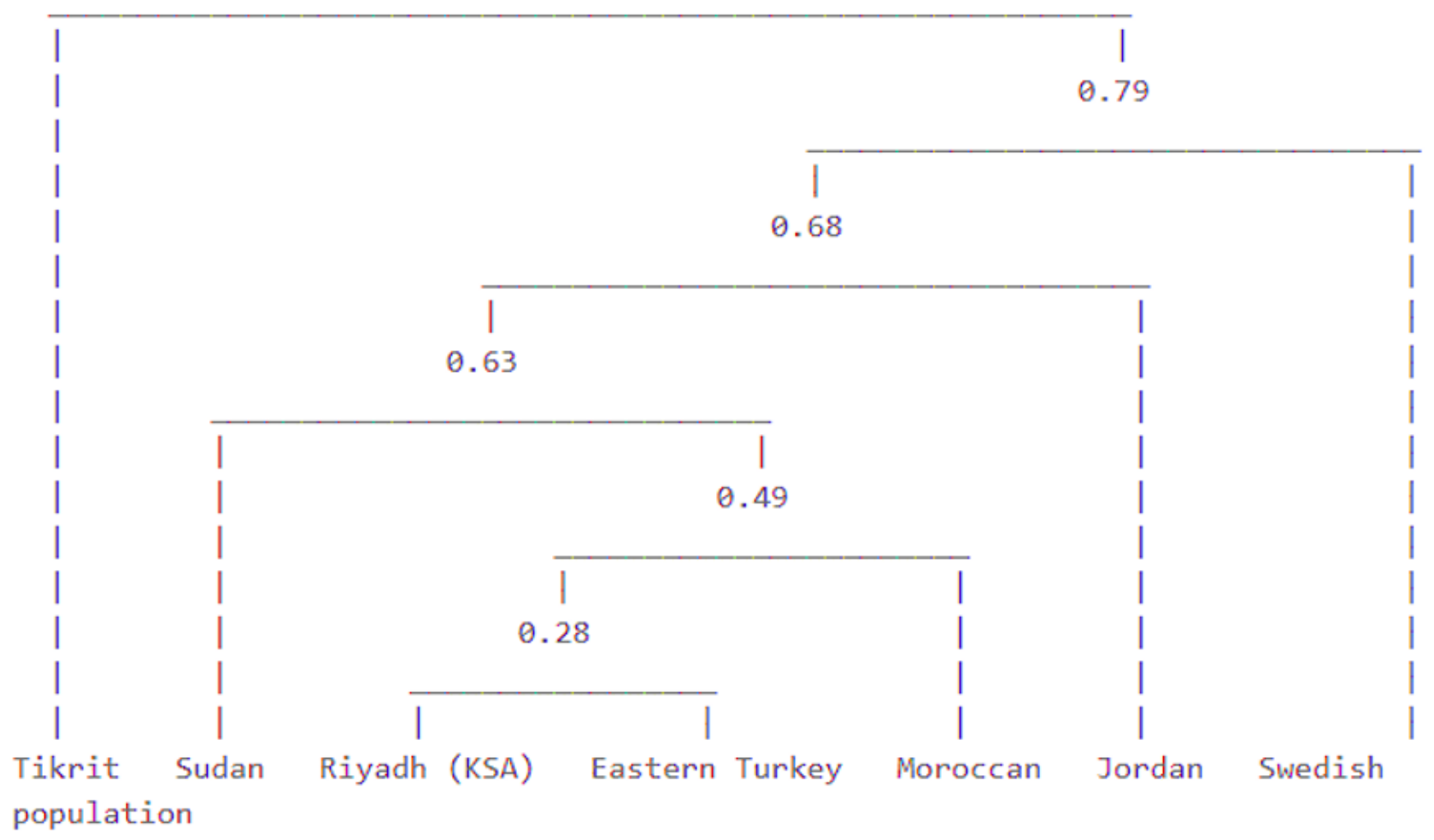

Figure 4. Dendrogram represent the level of similarity between Tikrit population- Iraqi and some international populations; including Jordan, Riyadh KSA, Eastern Turkey, Moroccan, Sudan, and Swedish. 


\section{CONCLUSION}

D2S1338, D18S51, D19S433 and D21S11 markers showed to be convenient for forensic genetics analysis in Tikrit population. Also, the data of STRs markers produced information used in the evaluation of genetic distances between genetics data of Tikrit population and some chosen population groups (Iraqi national and foreign populations). These data could be useful to enrich Iraqi STRs database and provide reference data for future studies in the population genetics field.

\section{ACKNOWLEDGEMENTS}

We would like to express our gratitude to the people of Tikrit / Iraq who donated samples. We would also like to express our appreciation to Basrah University, College of ScienceDepartment of Biology, particularly Prof. Dr. Adnan Issa AL-Badran and Dr. Bassim Muften Ohied Medan Al-Lamy.

\section{REFERENCES}

Adnan, A., Rakha, A., Nazir, S., Rehman, Z., Lu, J., \& Xuan, J. F. 2020. Genetic characterization of 15 autosomal STRs in the interior Sindhi population of Pakistan and their phylogenetic relationship with other populations. International Journal of Immunogenetics 47(2): 149-157.

Alaeddini, R. 2012. Forensic implications of PCR inhibition-a review. Forensic Science International: Genetics 6(3): 297-305.

Al-Eitan, L. N. \& Tubaishat, R. R. 2018. Evaluation of forensic genetic efficiency parameters of 22 autosomal STR markers (PowerPlex ${ }^{\circledR}$ Fusion system) in a population sample of Arab descent from Jordan. Australian Journal of Forensic Sciences 50(1): 97-109.

Al-Quraishi, A. M. F. \& Negm, A. M. 2019. Environmental remote sensing and GIS in Iraq. Springer-Water, Springer, Cham.

Al-janabi, T. Y., Al-zubaidi, M. M., \& Namaa, D. S. 2016. Allele frequency of 15 autosomal short tandem repeat ( STR ) loci in Al Anbar - Iraqi population. Iraqi Journal of Biotechnology 15(2): 1-8.

Al-Rubai, H. K., Al-Zubaidi, M. M., Ibrahem, H. K., Mohammed, A., Rashed, S., Hussam, R., Nabeel, S., Abdullateef, A., \& Abdulkaduhm, A. 2015. Revealed of A novel allele in Wasit - Iraqi population. Iraqi Journal of Science 56(4A): 2798-2806.

Al-Snan, N. R., Messaoudi, S., Babu, S. R., \& Bakhiet, M. 2019. Population genetic data of the 21 autosomal STRs included in GlobalFiler kit of a population sample from the Kingdom of Bahrain. PLOS ONE 14(8): 1-14.

Ariffin, S. H. Z., Wahab, R. M. A., Zamrod, Z., Sahar, S., Abd
Razak, M. F., Ariffin, E. J., \& Senafi, S., 2007. Molecular archeology of ancient bone from 400 year old shipwreck. Asia Pacific Journal of Molecular Biology \& Biotechnology 15(1): 27-31.

Babiker, H. M. A., Schlebusch, C. M., Hassan, H. Y., \& Jakobsson, M. 2011. Genetic variation and population structure of Sudanese populations as indicated by 15 Identifiler sequence-tagged repeat (STR) loci. Investigative Genetics 2(1).

Bentayebi, K., Abada, F., Ihzmad, H., \& Amzazi, S. 2014. Genetic ancestry of a Moroccan population as inferred from autosomal STRs. Meta Gene 2: 427-438.

Bradford, A. S. 2001. With Arrow, Sword, and Spear: A History of Warfare in the Ancient World. Greenwood Publishing Group.

Buadu, S., 2018. Forensic DNA genotyping by means of next generation sequencing. Analysis of Autosomal STRs of a Norwegian population sample using the ForenSeq FGx system (Master's thesis, UiT Norges arktiske universitet).

Chbel, F., Nadifi, S., Martinez-Bouzas, C., Louahlia, S., Azeddoug, H., \& Martinez De Pancorbo, M. 2003. Population genetic data of eight tetrameric short tandem repeats (STRs) in Casablanca resident population to use in forensic casework. Forensic Science International 132(1): 82-83.

Delgado, E. \& Neyra, C. D. 2019. Allele frequencies of 21 autosomal STR markers in a mixed race Peruvian population applied to forensic practice. Spanish Journal of Legal Medicine 45(3): 92-97.

El Andari, A., Daouk, A., \& Mansour, I., 2018. Effect of DNA profile size, reference population database, and parents availability on parentage testing in consanguineous and endogamous populations: The Lebanese case. Journal of Forensic Research 9(425): 2.

El Amri, H., Squalli, D., Gazzaz, B., Hajri, A. E. H., \& El Ossmani, H. 2011. Genetic structure of Moroccan population using 15 STRs of NGM kit. Forensic Science International: Genetics Supplement Series 3(1): e534-e535.

Excoffier, L., Hofer, T., \& Foll, M. 2009. Detecting loci under selection in a hierarchically structured population. Heredity 103(4): 285-298.

Garrigan, D. \& Hammer, M. F. 2006. Reconstructing human origins in the genomic era. Nature Reviews Genetics 7(9): 669680.

GE Healthcare. 2010. Reliable extraction of DNA from WhatmanTM FTATM cards (28-9822-22 AA). Sample collection, 8 .

Glaubitz, J. C. 2004. Convert: a user-friendly program to reformat diploid genotypic data for commonly used population genetic software packages. Molecular Ecology Notes 4(2): 309310.

Gymrek, M. 2017. A genomic view of short tandem repeats. Current Opinion in Genetics \& Development 44: 9-16.

Haidar, M., Abbas, F. A., Alsaleh, H., \& Haddrill, P. R. 2021. Population genetics and forensic utility of 23 autosomal PowerPlex Fusion 6C STR loci in the Kuwaiti population. Scientific Reports 11(1): 1-11.

Hale, M. L., Burg, T. M., \& Steeves, T. E. 2012. Sampling for microsatellite-based population genetic studies: 25 to 30 individuals per population is enough to accurately estimate allele frequencies. PloS ONE 7(9): e45170.

Hameed, I. H., Ommer, A. J., Murad, A. F., \& Mohammed, G. J. 2015. Allele frequency data of 21 autosomal short tandem repeat loci in Mesan and Basrah provinces in South Iraq. Egyptian Journal of Forensic Sciences 5(4): 150-156.

Hildebrand, C. E., David, C., Torney, C., \& Wagner, P., 1994. Informativeness of polymorphic DNA markers. Los Alamos Science 20: 100-102.

Hunter, P. 2007. Dig this: Biomolecular archaeology provides new insights into past civilizations, cultures and practices. 
EMBO Reports 8(3): 215-217.

Montelius, K., Karlsson, A. O., \& Holmlund, G. 2008. STR data for the AmpFlSTR identifiler loci from Swedish population in comparison to European, as well as with nonEuropean population. Forensic Science International: Genetics 2(3).

Murad, M. J. \& Amin, B. K. 2017. A microsatellite study for determination of allelic variation of Kurdish populationKurdistan region-Iraq. 020036 (September). AIP Publishing LLC.

Osman, A. E. \& Alsafar, H. 2015. Autosomal short tandem repeat (STR) variation based on 15 loci in a population from the central region (Riyadh Province) of Saudi Arabia. Journal of Forensic Research 06(01): 6-10.

Padmanabhan, S. 2014. Handbook of pharmacogenomics and stratified medicine. Academic Press.

Perez, M. F., Franco, F. F., Bombonato, J. R., Bonatelli, I. A. S., Khan, G., Romeiro-Brito, M., Fegies, A. C., Ribeiro, P. M., Silva, G. A. R., \& Moraes, E. M. 2018. Assessing population structure in the face of isolation by distance: Are we neglecting the problem? Diversity and Distributions 24(12): 1883-1889.

Pilav, A., Pojskić, N., Kalajdžić, A., Ahatović, A., Džehverović, M. and Čakar, J., 2020. Analysis of forensic genetic parameters of 22 autosomal STR markers (PowerPlex ${ }^{\circledR}$ Fusion System) in a population sample from Bosnia and Herzegovina. Annals of Human Biology 47(3): 273-283.

Pyeritz, R. E., Korf, B. R., \& Grody, W. W. 2018. Emery and Rimoin's principles and practice of medical genetics and genomics: Foundations. Academic Press.

Quiroz-Mercado, J. A., Ríos-Rivas, R. J., Martínez-Sevilla, V. M., Chávez-Marín, G., Jaimes-Díaz, H., Santiago-Hernández, J. C., Maldonado-Rodríguez, R., Rangel-Villalobos, H. 2017. Analysis of fortuitous matches in a STR genotype database from Mexico and its forensic efficiency parameters. Egyptian Journal of Forensic Sciences 7(1): 1-9.

Reinar, W. B., Knutsen, J. B., Jentoft, S., Tørresen, O. K., Butenko, M. A., \& Jakobsen, K. S. 2018. Evolutionary adaptability linked to length variation in short genic tandem repeats. BioRxiv: 310045.

Rosenberg, N. A., Mahajan, S., Ramachandran, S., Zhao, C., Pritchard, J. K., \& Feldman, M. W. 2005. Clines, clusters, and the effect of study design on the inference of human population structure. PLoS Genetics 1(6): 0660-0671.

Rousset, F. 2016. GENEPOP ' 007: a complete reimplementation of the GENEPOP. January 2008.

Silva, N. M., Pereira, L., Poloni, E. S., \& Currat, M. 2012. Human Neutral Genetic Variation and Forensic STR Data. PLoS ONE 7(11).

Tokdemir, M., Tunçez, F. T., \& Vicdanli, N. H. 2016. Population Genetic data for 15 Autosomal STR markers in Eastern Turkey. Gene 586(1): 36-40.

Yoo, S. Y., Cho, N. S., Park, M. J., Seong, K. M., Hwang, J. H., Song, S. B., Han, M. S., Lee, W. T., \& Chung, K. W. 2011. A large population genetic study of 15 autosomal short tandem repeat loci for establishment of Korean DNA Profile Database. Molecules and Cells 32(1): 15-19. 